\title{
The effect of surgical operation on leg venous flow measured with radioactive hippuran
}

\author{
J. V. Harvey Kemble* \\ M.A., F.R.C.S. \\ The Middlesex Hospital, London
}

\section{Summary}

The velocity of venous blood flow in the legs has been measured in patients before and after operation using ${ }^{125}$ I hippuran.

Immediately after operation there was a profound slowing of venous flow to about half the pre-operative rate. On the day following operation the rate had returned to the pre-operative level.

The effect of elevation of the legs has been investigated. Leg elevation approximately doubled the rate of flow.

The value of leg elevation as a measure in the prevention of deep vein thrombosis is discussed in the light of these findings. The paper provides evidence that the practice of elevation of the legs during and after operation increases venous flow rate.

\section{Introduction}

It is now widely believed that the thrombosis of veins in the legs which occurs postoperatively is caused at least in part by venous stasis (Boyd, 1947; Hadfield, 1950; Gibbs, 1957).

That thrombosis occurs in situations in which blood stagnation is maximal has been shown by Paterson \& McLachlin (1954) in necropsy studies; the youngest thrombi are found in areas of eddying such as vein valve pockets, from where they may propagate.

The relationship between venous thrombosis and disturbances of the circulation has been recognized since the time of Virchow (1856), but until the radioactive iodine method of detecting deep vein thrombosis was described (Atkins \& Hawkins, 1965), the diagnosis of the condition depended largely on physical signs, since shown to be a very imperfect method.

With the new method of diagnosis, it is becoming increasingly clear that postoperative deep vein thrombosis begins at the time of, or within a few hours of operation. It is therefore logical that factors which alter at the time of operation or soon after should be investigated in the search for causes of venous thrombosis.

* Present address: Queen Mary's Hospital, Roehampton, London, S.W.15.
The present study was therefore undertaken in order to quantify what alteration in venous blood flow occurs in the legs during the operative period, and to investigate by how much elevation of the legs changed this flow rate.

\section{Materials and method}

Thirty-two patients, seventeen male and fifteen female were volunteers to the study. A few of these were investigated on more than one occasion. These thirty-two represent the residuum of patients after a number have had to be excluded from the survey due to inability to obtain adequate data for technical reasons.

The operations which the patients underwent were mostly major abdominal such as gastrectomy, retropubic prostatectomy, colectomy and vagotomy with drainage (Table 1). The general anaesthetic used varied, and no conclusions regarding the effect of different anaesthetics on flow rates have been made.

The measurements of venous flow velocity in the legs were undertaken on the day before operation, immediately after operation (within $60 \mathrm{~min}$ of the discontinuation of the anaesthetic gases) and on the day after operation.

The flow velocity in the legs was measured by means of a radioactive tracer. ${ }^{125}$ I hippuran was chosen because it has a biological half life of less than $1 \mathrm{hr}$.

On the day before the first investigation and for 5 days postoperatively the patient was given $150 \mathrm{mg}$ of potassium iodide by mouth to saturate the thyroid. Because of any possible radiation hazard to the gonads, the investigation was confined to

TABLE 1. Operations studied in the investigation

\begin{tabular}{lc}
\hline \multicolumn{1}{c}{ Operation } & No. of cases \\
\hline Cholecystectomy & 7 \\
Colectomy & 4 \\
Gastrectomy & 3 \\
Hiatus hernia (abdominal repair) & 1 \\
Hip arthroplasty & 3 \\
Pharyngolaryngectomy & 1 \\
Retropubic prostatectomy & 8 \\
Vagotomy and drainage & 5 \\
\hline
\end{tabular}


patients over the age of 45 years. To ensure comparability of conditions, the patients had all been at rest in bed, lying supine with the legs horizontal, for a minimum of 20 min before the investigation was undertaken. The patients were covered with a sheet and blanket until immediately before measurements were made to minimize temperature differences.

A small volume $(0.2 \mathrm{ml})$ of ${ }^{125} \mathrm{I}$ hippuran $(5 \mu \mathrm{Ci})$ was injected rapidly into a dorsal foot vein by means of a 1-ml tuberculin syringe. The arrival of the isotope in the deep veins of the calf was detected by a scintillation counter. The counter was placed immediately above a tourniquet around the ankle which occluded the superficial veins. A second scintillation counter was positioned over the femoral vein just below the inguinal ligament.

The scintillation counters were connected to two ratemeters (Echo M5190), and the arrival of the isotope opposite each counter was recorded by a two-pen recorder writing on calibrated paper moving at $1 \mathrm{~cm} / \mathrm{sec}$ (Fig. 1). The blood flow velocity was calculated by measuring the distance between the two counters and dividing by the time taken for the radioactive bolus to pass from the ankle to the groin counter. It was expressed in $\mathrm{cm} / \mathrm{sec}$.

\section{Results}

In order to establish the reproducibility of the method, duplicate and triplicate studies of leg-flow rate were carried out on fifteen legs at different times on the same day, with the legs in the same position on each occasion. The standard errors ranged from 0 to $1 \cdot 0$, with an average of 0.43 . The differences that occurred between paired and tripled measurements was of the order of $10-15 \%$. Alterations of a few percent in any one subject therefore were not significant, but changes greater than this were.

The rate of venous flow immediately after operation was compared with the rate of flow on the preoperative day. Thirty legs were studied.

The mean rate of flow in fifteen left legs measured before operation was $3 \cdot 14 \mathrm{~cm} / \mathrm{sec}$. Immediately after operation, this fell to a mean of $1.22 \mathrm{~cm} / \mathrm{sec}$. This was a fall of $61 \cdot 1 \%$ and was significant $(P<0.005)$.

The mean rate of flow in fifteen right legs preoperatively was $2.87 \mathrm{~cm} / \mathrm{sec}$. Immediately after operation, this fell to $1.51 \mathrm{~cm} / \mathrm{sec}$. This was a fall of $47 \cdot 3 \%$ and was significant $(P<0.05)$ (Table 2$)$.

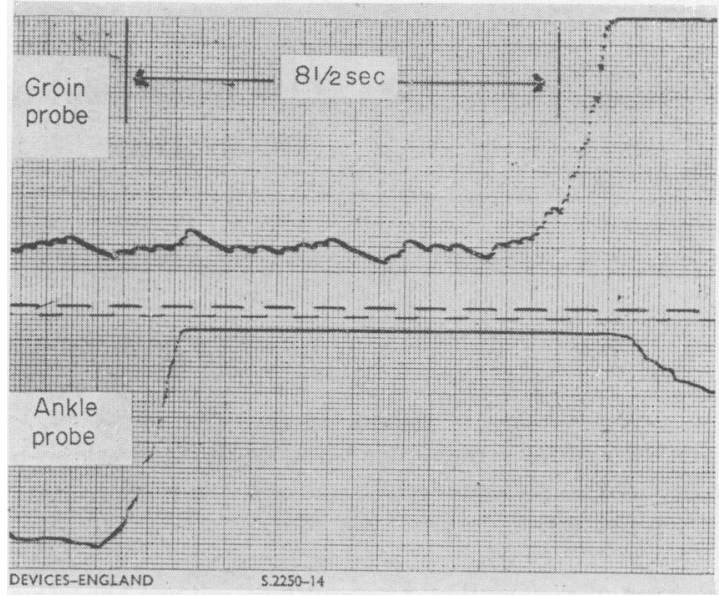

Fig. 1. The trace of the pen recorder indicating the time of arrival of the radioactive isotope opposite each scintillation counter probe, when the count rises abruptly.

The mean rate of flow before operation was theno compared with the mean rate of flow on the dap after operation. Thirty-eight legs were studied. There $\mathbb{D}$ was no significant difference between these two rates: By the day following operation, the flow rate had returned to its pre-operative level.

The effect on the venous flow rate of elevating the legs on a $10^{\circ}$ wedge placed under the heel and calf was studied. The base of the wedge raised the heel 4 in. above the horizontal. This position was maintained for $5 \mathrm{~min}$ before measurements were made. Fourteen left legs and twenty-one right legs were studied.

Table 3 shows the values for the mean rates of flow with the leg in the horizontal and the elevated positions. The effect of elevation was to increase the flow rate by 3.04 times the rate with the leg horizontal for the left leg, and by 1.44 times for the right leg. For both left and right legs the alteration in the flow rate produced by elevation was significant $(P<0.001$ and $P<0.025$ ).

The rate of venous flow in right and left legs was compared. Seventy-six pairs of legs were studied. The mean flow rate in the left legs was $3.51 \mathrm{~cm} / \mathrm{sec}$ $( \pm 0 \cdot 37)$, and in the right legs $2 \cdot 87 \mathrm{~cm} / \mathrm{sec}( \pm 0 \cdot 23)$. The difference was significant $(P<0.05)$.

TABLE 2. Venous flow rate immediately following operation compared with the rate before operation

\begin{tabular}{lccccc}
\hline & \multicolumn{2}{c}{ Pre-operative } & & \multicolumn{2}{c}{ Operative } \\
\cline { 2 - 3 } & $\begin{array}{c}\text { Mean flow rate } \\
(\mathrm{cm} / \mathrm{sec})\end{array}$ & Standard error & & $\begin{array}{c}\text { Mean flow rate } \\
(\mathrm{cm} / \mathrm{sec})\end{array}$ & Standard error \\
\hline Left leg & 3.14 & 0.48 & 1.22 & 0.20 & $<0.005$ \\
Right leg & 2.87 & 0.52 & & 1.51 & 0.24 \\
\hline
\end{tabular}


TABLE 3. The venous flow rate with the legs horizontal compared with that with the legs elevated $10^{\circ}$

\begin{tabular}{|c|c|c|c|c|c|}
\hline & \multicolumn{2}{|c|}{ Horizontal } & \multicolumn{2}{|c|}{ Elevated $10^{\circ}$} & \multirow{2}{*}{ Probability } \\
\hline & $\begin{array}{l}\text { Mean flow rate } \\
(\mathrm{cm} / \mathrm{sec})\end{array}$ & Standard error & $\begin{array}{l}\text { Mean flow rate } \\
(\mathrm{cm} / \mathrm{sec})\end{array}$ & Standard error & \\
\hline $\begin{array}{l}\text { Left leg } \\
\text { Right leg }\end{array}$ & $\begin{array}{l}2 \cdot 65 \\
2 \cdot 86\end{array}$ & $\begin{array}{l}0.40 \\
0.50\end{array}$ & $\begin{array}{l}8 \cdot 05 \\
4 \cdot 11\end{array}$ & $\begin{array}{l}1.44 \\
0.53\end{array}$ & $\begin{array}{l}<0.001 \\
<0.025\end{array}$ \\
\hline
\end{tabular}

\section{Discussion}

The significance of venous stagnation as a cause of venous thrombosis has been acknowledged since the time of Virchow. There have been several studies on venous flow in the postoperative period, but apart from a few most have concentrated on the changes that occur in the several days which follow operation rather than the immediate operative period.

Bellis, Doss \& Craft (1943), using the sodium cyanide method, measured ankle to carotid flow time. They found a reduced circulation time in the postoperative period which they attributed to increased respiration and pulse rate and to increased temperature. Dependency of the limb slowed the rate. Elevation, however, above the horizontal did not accelerate it.

Frimann-Dahl (1935) showed that elevating the leg did increase flow rate, and he therefore advocated elevation of the foot of the bed after operation. Lanzara (1939), using the decholin time, found shortened circulation times after operation and this has been confirmed by Doran, Drury \& Sivyer (1964), who measured flow rate by direct cannulation of a foot vein. Wright, Osborn \& Edmonds (1951) found a slightly increased venous flow rate at the end of operation, but their series contained a large number of gynaecological operations in which the removal of pelvic tumours may have been the cause of the improved flow rates.

The finding of diminished flow rates during and immediately after operation may explain the occurrence of deep vein thrombosis at this time. Necropsies indicate that venous thromboses originate, in the main, in the deep veins of the calf, in the intramuscular veins and the soleal sinuses (Sevitt \& Gallagher, 1961; Gibbs, 1957). During operation, particularly with the use of relaxant drugs, there is a profound stagnation of blood in these sites as the muscles become atonic. During anaesthesia, several factors which normally aid venous blood flow from the legs are deranged. Levi \& Lewison (1950) have specified factors on which venous blood flow depends: the sectional area of the venous bed, the muscle pump, and gravity. The muscle pump and gravity are certainly ineffective during most operations, and other factors such as cardiac output and total blood volume may be reduced in effectiveness.

Hirvonen \& Sonneschein (1962) showed in cats that venous flow rate could be increased by between three and six times the resting rate by stimulating the tibial nerve to gastrocnemius, and Negus \& Browse (1970), in a preliminary study, suggested that electrical stimulation of calf muscles during operation reduced the incidence of venous thrombosis. This has been confirmed (Browse \& Negus, 1970).

A much more readily and universally applicable method of increasing blood flow is to elevate the legs during and after operation. This expedient increases venous flow rate by between one-and-a-half and three times the horizontal flow rate. Our figures correspond well with those of Wright \& Osborn (1952) who found a two-fold increase in the flow rate by tilting the whole patient head down $10^{\circ}$. Clarke $\&$ Cotton (1968) stated that the effect on blood flow in the legs of tilting the patient lasted for only 2 or $3 \mathrm{~min}$, but we have not found this to be so.

Makin (1969) demonstrated that venous blood flow in the legs could be increased by the application of compression stockings. The venous flow rate in the stockinged leg was up to five times faster than in the unstockinged leg. In the patients over 51 years, the wearing of compression stockings during and after surgical operation produced a significant reduction in the incidence of postoperative deep vein thrombosis.

It has yet to be demonstrated that the marked increase in venous flow rate produced by leg elevation does indeed lower the incidence of venous thrombosis. Rosengarten \& Laird (1971) in a small series of twenty-five patients suggested that leg elevation during and after operation did not give this protection.

We have undertaken a survey of patients having major surgery in whom one or other leg was elevated on a $10^{\circ}$ wedge beneath the heel for the duration of surgery and for $1 \mathrm{hr}$ afterwards. The leg to be elevated was selected randomly. After operation, the patients were given an intravenous injection of ${ }^{125} I$ fibrinogen and the legs were scanned daily until the tenth postoperative day with a scintillation counter for evidence of deep vein thrombosis (Negus et al., 1968).

To date, twenty-seven patients have been studied. Thirteen left legs and fourteen right legs were elevated. Deep vein thrombosis has been detected in eight patients or ten legs (two patients had bilateral thromboses). The non-elevated leg developed deep 
vein thrombosis in six cases and the elevated leg in four cases.

We do not regard the results from so small a series of twenty-seven patients and 10 thromboses as having significance, and consider the case for or against leg elevation as a prophylactic against deep vein thrombosis not yet proven. The investigation is therefore continuing and it is anticipated that a very much larger number of patients will need to be studied.

It seems unlikely that the very marked increase in venous flow rate which results from leg elevation has no effect on the incidence of deep vein thrombosis. Such evidence as there is suggests that elevation of the legs increases the clearance of blood from the legs by as much, if not more, than exercising the muscles in the horizontal position (McLachlin et al., 1960). In Doran's series (Doran et al., 1964), despite electrical stimulation of the calf muscles, venous stasis persisted in thirteen out of nineteen patients, and the maximum improvement in venous flow rate he noted was four times the rate of the unstimulated leg. The maximum flow rate in our series in the elevated leg was six times that of the horizontal leg.

Unless the intermittent effect of change in venous flow rate which results from muscle contraction is the crucial factor in the prevention of venous thrombosis (which seems unlikely in view of Makin's findings, Makin et al., 1969), there would appear to be no reason to suspect that the increase in venous flow which results from leg elevation is not as effective in preventing deep vein thrombosis as electrical stimulation of the calf during and after operation.

\section{Acknowledgments}

The author wishes to thank Mr Neville Brown for help with the scintillation counter, Dr Brian Newman for statistical advice, the Surgeons of the Middlesex Hospital for permission to study their patients, and in particular Professor L. P. Le Quesne.

\section{References}

Atkins, P. \& Hawkins, L.A. (1965) Detection of venous thrombosis in the legs. Lancet, ii, 1217.

Bellis, C.J., Doss, A.K. \& Craft, C.B. (1943) Circulation rate after operation. Surgery, 13, 35.
Boyd, W. (1947) Surgical Pathology, 6th edn. Saunders, Philadelphia.

Browse, N.L. \& Negus, D. (1970) Prevention of leg vein $>$ thrombosis by electrical muscle stimulation. British Medical Journal, 3, 615 .

Clarke, C. \& Cotton, L.T. (1968) Blood flow in deep veins of leg. British Journal of Surgery, 55, 211.

Doran, F.S.A., DruRY, M. \& Sivyer, A. (1964) Venous stasis during operation. British Journal of Surgery, 51,486 .

FrimanN-DahL, J. (1935) Postoperativ rontgenuntersuchungen. Acta chirurgica Scandinavica, 76, 5.

GiBBS, N.M. (1957) Venous thrombosis of the lower limbs with reference to bed rest. British Journal of Surgery, 45, 209.

Hadfield, G. (1950) Thrombosis. Annals of the Royal College $\vec{\circ}$ of Surgeons of England, 6, 219.

Hirvonen, L. \& SonNensChein, R.A. (1962) Relation between blood flow and contraction. Circulation Research, 10, 94.

Lanzara, A. (1939) Il tempo di Circolazione del sangue. Policlinico, 46, 297.

LEVI, J.E. \& LEwISON, E.F. (1950) Venous velocity in the leg measured with radioactive sodium. Bulletin of the Johns Hopkins Hospital, 86, 370.

MaKIN, G.S. (1969) Trial of tubigrip to prevent deep venous thrombosis. British Journal of Surgery, 56, 373.

McLachlin, A.D., McLaChlin, J.A., JoRY, T.A. \& RawLING, E.G. (1960) Venous stasis in the lower extremities. Annals of Surgery, 152, 678.

Negus, D. \& Browse, N.L. (1970) Calf muscle stimulation in the prevention of deep vein thrombosis. Europed Surgical Research, 2, 134.

Negus, D., Pinto, D.J., LeQuesne, L.P., Brown, N. Chapman, M. (1968) ${ }^{125}$ I labelled fibrinogen in the dio gnosis of deep vein thrombosis. British Journal of Surgerg, 55, 835.

Paterson, J.C. \& McLachlin, J. (1954) Precipitating factor in venous thrombosis. Surgery, Gynaecology and Obstetrie 98, 96.

Sevitt, S. \& Gallagher, N. (1961) Venous thrombosis and pulmonary embolism. A clinico-pathological study in injured and burned patients. British Journal of Surgery, 48, 475.

RosengaRTEN, D.S. \& LAIRD, J. (1971) Effect of leg elevation in the incidence of postoperative deep vein thrombosis. British Journal of Surgery, 58, 182.

VIRCHOW, R.L.K. (1856) Thrombose und Embolie. Meidinger, Frankfurt.

WRIGHT, H.P., OSBORN, S.B. \& EDMONDS, D.G. (1951) Effect of postoperative bed rest and early ambulation on the rate of venous blood-flow. Lancet, i, 22.

WRIGHT, H.P. \& OSBORN, S.B. (1952) Effect of posture on venous velocity, measured with ${ }^{24} \mathrm{NaCl}$. British Heart Journal, 14, 325. 